\title{
Gross morphometry of the heart of the Common marmoset
}

\author{
R. Senos ${ }^{1}, 2$, H.G. Benedicto ${ }^{1}$, C.M. del Rio do Valle2, 3 , R. del Rio do Valle ${ }^{3,4}$, P.L. Nayudu ${ }^{3}$, \\ J.R. Kfoury Junior ${ }^{2}$, P.P. Bombonato ${ }^{2}$ \\ ${ }^{1}$ Department of Morphology, Universidade Federal Fluminense, Brazil \\ ${ }^{2}$ Anatomy of the Domestic and Wild Animals Section, Universidade de São Paulo, Brazil \\ ${ }^{3}$ Reproductive Biology Unit, Deutsches Primatenzentrum, Brazil \\ ${ }^{4}$ Health Sciences Institute, Paulista University, Brazil
}

[Received 13 May 2013; Accepted 29 June 2013]

\begin{abstract}
The Callithrix jacchus is a Brazilian endemic species that has been widely used as an experimental model in biomedical research. Anatomical data are necessary to support experimental studies with this species. Eleven hearts of $C$. jacchus from the German Primate Centre (DPZ) have been studied in order to characterize their gross morphometry and compare them with other animal models and human. Biometric data were also obtained. The mean values for morphometry of the hearts did not show any significant difference between male and female. The relative heart weight was similar to human, bovine and equine species. Considering those aspects, the $\mathrm{C}$. jacchus could be used as non-human primate experimental model for biomedical studies on heart. (Folia Morphol 2014; 73, 1: 37-41)
\end{abstract}

Key words: anatomy, morphology, experimental model, primate, Callithrix jacchus, biometric

\section{INTRODUCTION}

The Common marmoset (Callithrix jacchus) is a Neotropical primate from Brazilian Cerrado region [21]. Although it is endemic in Brazilian Northeast, the inadvertent introduction into other regions have provided evidence of high adaptability to different habitats $[3,17,18,20]$.

This adaptable characteristic has led the species to captive life. In comparison to other non-human primate experimental models, the $C$. jacchus has shown advantages such as lower breeding costs, easier handling, biosafety and physiological similarities $[1,14,15]$. This way, the interest in marmoset data has developed significantly lately [22], as shown by scientific citations increasing from less than 100 in 1960 's to over 2700 in 1990's [1]. Actually, over than
2900 and 5200 scientific publications are found in PubMed and Scopus index, respectively, when searching "marmoset" as key word.

Regarding heart morphology, we found little information in literature $[9,26]$. However, diseases like myocardial fibrosis, chronic myocarditis and ventricle dilatation have been reported previously for captive individuals of $C$. jacchus $[4,7,16,24]$. To understand these and other heart pathologies, i.e., related to toxicological studies [5], it is critical to establish normal characteristics and morphological data. In addition, species database has great value to veterinary medical care [12] and biodiversity.

Considering the scant information of $C$. jacchus heart morphology, we have studied the gross mor-

Address for correspondence: R. Senos, Rua Prof Hernani de Melo, 101 CEP 24210-130 Niteroi, RJ, Brazil, tel: +55 2199760220 , 
phometry to provide basic information for further anatomical, physiological and physiopathological studies. We also took biometric data to characterize the studied specimens.

\section{MATERIALS AND METHODS}

We used 11 hearts from 5 male and 6 female of C. jacchus, adults ranging from 2.5 to 8 years old. All animals were born and kept in captivity under controlled conditions of 12 light hours daily, $55 \pm 10 \%$ humidity and $25 \pm 3^{\circ} \mathrm{C}$ temperature at German Primate Centre (DPZ) colony. The specimens were fed with chicken and bovine cooked meat, primate pelletised ration, cat pelletised ration, season fruits, vegetables, bread, milk and ad libidum water. Meal worms were provided twice a week. Pregnant specimens were not used.

All samples were obtained at DPZ from animals which were euthanised for other experiments under DPZ standard procedures in OP theatre (German permission Az.: 509.42502/08-01.03) and transferred under register number $0100 / 06$ to Universidade de Sao Paulo (USP) where the protocols were approved and certified under register number $1894 / 2010$ by the Bioethic Commission of the School of Veterinary Medicine and Animal Science of USP in agreement to ethical principles in animal research.

After euthanasia, specimens were weighed and body measures were taken. The thoracic perimeter was taken in thorax caudal third.

Thorax was opened by section of the costochondral joints exposing the heart which was dissected preserving the great vessels in standard length close to heart base to not interfere the weight measurement of the organ.

The hearts were fixed in aqueous $10 \%$ formalin solution after cleaning using isotonic saline solution.

The heart gross morphometry (ventricle high, lateral width, dorsal-ventral width, perimeter and ventricles thickness) was taken using Mitutoyo ${ }^{\circledR}$ CD-8" CX-B digital calliper. The ventricle height was established from the coronary sulcus to apex in the atrial face. Widths were taken in largest possible measure considering both atrial and auricular faces. The perimeter measurement was done based on coronary sulcus. Right and left ventricle thickness was taken in the middle third of each ventricle wall after dissection.
Volumetric value was obtained using Scherle method [13].

For statistical analyses, 3 groups were used: males, females and both. Average, median and standard deviation were obtained for each group. Statistical comparisons between male and female group were practiced using T-Student considering $\alpha=5 \%$ in agreement to Rodrigues [19].

\section{RESULTS}

The heart occupied the major part of the middle mediastinum. The shape was similar to an irregular cone and the base was connected to great vessels while the rest of the structures were free into the pericardium (Fig. 1).

Heart measurements and biometric data are presented in Table 1.

\section{DISCUSSION}

Our results presented no biometric differences between males and females in T-Student test. This is in agreement to reference [22] that indicates the marmosets are sexually monomorphic. In comparison to Valle [25], the thoracic perimeter of the males in our study was wider. This is coherent to body proportion once the specimens from National Primate Centre in Brazil (CENP) were lighter and smaller than ours.

Regarding to body weight, our results did not meet significant differences between males and females. When checking the references, free living specimens seem to be lighter than captive ones $[2,3,9,25]$. It probably occurs because free living animals have different diet and higher activity level due to territory defense, searching food and running away from predators. Considering the captive animals, our results for absolute weight values are in agreement to Clarke [6]. However, Wadsworth et al. [26], and Araújo et al. [2] have found much lighter specimens. We believe that the differences between the previous studies are not related only to genetic components but especially to caloric diets. This means that probably our specimens were overweighed or had obesity tendency.

Other notable finding in our data was the positive relation between the weight of the heart and the weight of the respective body, called relative weight of heart. This positive relation was also found in other studies $[9,26]$. However, our absolute values were in agreement only to $350 \mathrm{~g}$ adult 

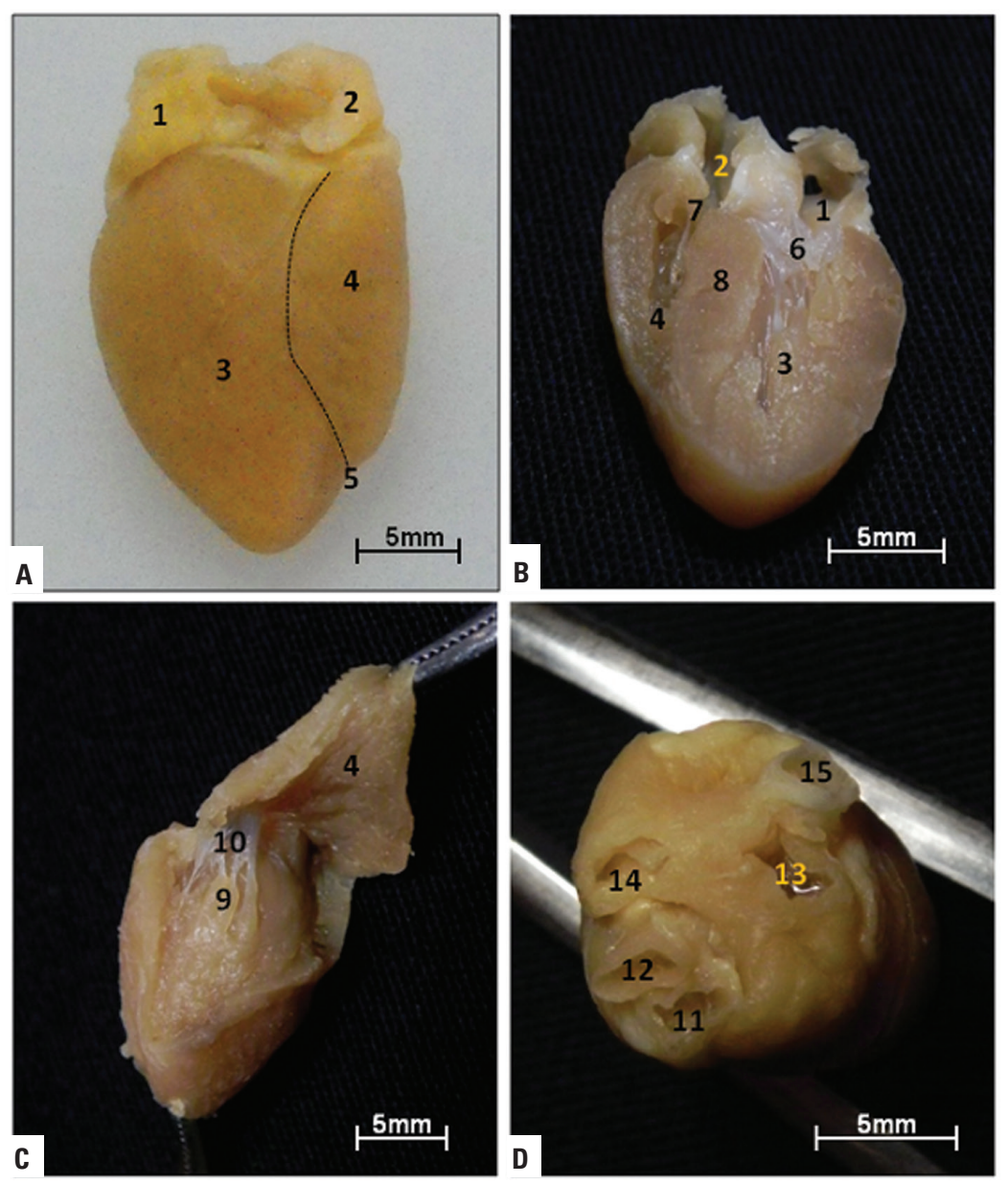

Figure 1. Hearts of the Callithrix jacchus in facies auricularis view $(\mathbf{A})$; longitudinal section $(\mathbf{B})$; right view after dissection of the ventricle wall (C); dorsal view; basis cordis (D); 1 - auricular sinistra; 2 - auricular dextra; 3 - ventriculus sinister; 4 - ventriculus dexter; 5 - sulcus interventricularis paraconalis; 6 — valva atrioventricularis sinistra; 7 - valva atrioventricularis dextra; 8 - septum interventriculare; 9 musculus papillaris; 10 - chordate tendineae; 11 - truncus pulmonalis; 12 - aorta; 13 - venae pulmonales; 14 - vena cava cranialis; 15 - vena cava caudalis.

Table 1. Biometric and morphometric values of 11 studied specimens (grouped or not) of Callithrix jacchus

\begin{tabular}{|c|c|c|c|c|}
\hline Aspect & Both gender \pm SD & Males \pm SD & Females \pm SD & $\mathbf{P}$ (t-Student test) \\
\hline Age [year] & $5.77 \pm 2.10$ & $6.5 \pm 1.12$ & $5.17 \pm 2.62$ & 0.32 \\
\hline Weight $[\mathrm{g}]$ & $457.80 \pm 65.61$ & $421 \pm 88.73$ & $482.33 \pm 34.92$ & 0.16 \\
\hline Specimen thoracic perimeter [cm] & $15.09 \pm 1.43$ & $14.8 \pm 1.57$ & $15.33 \pm 1.4$ & 0.56 \\
\hline Weight of heart $[\mathrm{g}]$ & $2.63 \pm 0.35$ & $2.75 \pm 0.33$ & $2.53 \pm 0.36$ & 0.38 \\
\hline Relative weight [\%] & $0.51 \pm 0.38$ & $0.61 \pm 0.15$ & $0.52 \pm 0.08$ & 0.27 \\
\hline Ventricular height [mm] & $18.05 \pm 0.84$ & $18.05 \pm 0.41$ & $18.04 \pm 1.13$ & 0.98 \\
\hline Lateral width $[\mathrm{mm}]$ & $15.37 \pm 0.81$ & $15.33 \pm 0.66$ & $15.40 \pm 0.98$ & 0.9 \\
\hline Dorsal-ventral width [mm] & $13.83 \pm 0.99$ & $13.68 \pm 1.07$ & $13.96 \pm 1.0$ & 0.66 \\
\hline Heart perimeter [mm] & $47.57 \pm 4.43$ & $49.52 \pm 3.04$ & $45.96 \pm 4.99$ & 0.2 \\
\hline Left ventricular thickness [mm] & $4.26 \pm 0.32$ & $4.24 \pm 0.21$ & $4.28 \pm 0.41$ & 0.84 \\
\hline Right ventricular thickness [mm] & $2.09 \pm 0.26$ & $2.03 \pm 0.19$ & $2.14 \pm 0.33$ & 0.53 \\
\hline
\end{tabular}


specimens, not young, studied by Wadsworth et al. [26]. It can be explained considering animal age, once the development of each organ is different during the specimen growing. In addition, different equipment and weighting techniques could interfere in absolute values. Around differences on relative weight of heart between males and females, there was no statistical significance in present data. This corroborates the use of non-specific gender for cardiovascular experimental studies because the similarity of the charge and work of the heart. In comparison to the domestic animals, the $C$. jacchus is more useful as model for human studies because only bovines and equines have similar relative weight of the heart - charge of work - but they present different other physiological aspects $[10,23]$.

Our findings also presented similar gross anatomy between the heart of $C$. jacchus and the heart of human and domestic carnivorous $[8,10$, 11, 23].

In concern to morphometry of the heart, we did not find significant differences between males and females. This way, both serve well to evaluate morphometric changes promoted in heart diseases or experiments. No reference was found to further discussion of our results.

\section{CONCLUSIONS}

Although C. jacchus has been used extensively as experimental model to human in many different fields of biomedical research, more cardiovascular system information is necessary. Our study provided heart gross morphometric parameters regarding captive specimens and it indicates the species has great potential for using as model for cardiovascular studies, independently of the gender. Finally, it is important to understand the histological and physiological aspects of both free living and captive specimens because their biometric and anatomical differences.

\section{ACKNOWLEDGEMENTS}

We thank the Deutsches Primatenzentrum (DPZ) in Germany for the samples, the Coordenação de Aperfeiçoamento de Pessoal de Nível Superior (CAPES) for the financial aid, Professor Dr Timothy Moulton from University of State of Rio de Janeiro for revising this article and Dr Anamaria Szrajbman Vaz da Silva from Federal University of the State of Rio de Janeiro for statistical support.

\section{REFERENCES}

1. Abbott DH, Barnett DK, Colman RJ, Yamamoto ME, Schultz-Darken NJ (2003) Aspects of common marmoset basic biology and life history important for biomedical research. Comp Med, 53: 339-350.

2. Araújo A, Arruda MF, Alencar Al, Albuquerque F, Nascimento MC, Yamamoto ME (2000) Body weight of wild and captive common marmosets (Callithrix jacchus). Int J Primat, 21: 317-324.

3. Auricchio P (1995) Primatas do Brasil. Terra Brasilis, São Paulo.

4. Chalmers DT, Murgatroyd LB, Wadsworth PF (1983) A survey of the pathologies of marmosets (Callithrix jacchus) derived from a marmoset breeding unit. Lab Animals, 17: 270-279.

5. Chamanza R, Parry NMA, Rogerson P, Nicol JR, Bradley AE (2006) Spontaneous lesions of the cardiovascular system in Purposed-Bred Laboratory Nonhuman Primates. Toxicol Pathol, 34: 357-363.

6. Clarke JM (1994) The common marmoset (Callithrix jacchus). ANZCCART News, 7: 1-8.

7. David JM, Dick Jr EJ, Hubbard GB (2009) Spontaneous pathology of the common marmoset (Callithrix jacchus) and tamarins (Saguinus oedipus, Saguinus mystax). J Med Primat, 38: 347-359.

8. Evans HE (1993) Miller's anatomy of the dog. W.B. Saunders, Philadelphia.

9. Freitas Burity $\mathrm{CH}$, Mandarim-de-Lacerda CA (1995) The weight of the heart in Callithrix Erxleben, 1777. Bull Assoc Anat, 79: 21-24.

10. Getty R (1986) Sisson/Grossman Anatomia dos Animais Domésticos. Guanabara Koogan, Rio de Janeiro.

11. König HE, Liebich $\mathrm{H}$ (2004) Anatomia dos animais domésticos: texto e atlas colorido. Artmed, Porto Alegre.

12. Ludlage E, Mansfield K (2003) Clinical care and diseases of common marmoset (Callithrix jacchus). Comp Med, 53: $369-382$.

13. Mandarim-de-Lacerda CA (1994) Manual de quantificação morfológica: morfometria, alometria, esteriologia. Editora da Universidade Estadual do Rio de Janeiro, Rio de Janeiro.

14. Mansfield K. Marmosets models commonly used in biomedical research (2003) Comp Med, 53: 383-392.

15. Neusser M, Stanyon R, Bigoni F, Wienberg J, Muller S (2001) Molecular cytotaxonomy of New World Monkeys (Platyrrhini) - comparative analysis of five species by multicolor chromosome painting gives evidence for a classification of Callimico goeldii within the family of Callitrichidae. Cytonegen and Cell Gen, 94: 206-215.

16. Okazaki Y, Kurata Y, Makinodan F, Kidachi F, Youkoyama M, Yako Y, Yamagicshi Y, Katsuta O, Takechi M, Tsuchitani M (1995) Spontaneous lesions detected in the common cotton-eared marmosets (Callithrix jacchus). J Vet Med Sci, 58: 181-190.

17. Passos FC, Miranda JMD, Aguiar LM, Ludwig G (2006) Distribuição e ocorrência de primatas no Estado do Paraná, Brasil. In: Bicca-Marques JC ed. A Primatologia no Brasil 10. EDIPUCSRS: Porto Alegre (http://zoo.bio.ufrp.br/mamífero/ primatasprfinal.pdf). Accessed in Apr 19th 2010.

18. Pereira DG (2006) Interações entre espécies exóticas invasoras e espécies nativas: calitriquídeos no Parque Nacional da Serra dos Órgãos, Dissertation (Master in Environment 
Science) - Instituto de Geociências, Universidade Federal Fluminense, Niterói.

19. Rodrigues PC (2002) Bioestatítica. Editora da Universidade Federal Fluminense. Niterói.

20. Ruiz-Miranda CR, Affonso AG, Morais MM, Verona CE, Martins A, Beck B (2006) Behavioral and Ecological Interactions between Reintroduced Golden Lion Tamarins (Leotonpithecus Rosália, Linnaeus 1766) and Introduced Marmosets (Callithrix spp, Linnaeus 1758) in Brazil's Atlantic Coast Forest Fragments. Braz Arch Bio and Technol, 49: 99-109.

21. Rylands $A B$, Schneider $H$, Langguth $A$, Mittermeier RA, Groves CP, Rodriguez-Luna E (2000) An assessment of the diversity of new world primates. Neotrop prim, 8: 61-93.

22. Tardif S, Bales K, Williams L, Moeller EL, Abbott D, Schultz-Darken N, Mendoza S, Mason W, Bourgeois S, Ruiz J
(2006) Preparing new world monkeys for laboratory research. ILAR, 47: 307-315.

23. Testut $L$ (1911) Traité d'anatomie humaine. Octave Doin et Fils, Paris.

24. Tucker MJ (1984) A survey of the pathology of marmosets (Callithrix jacchus) under experiment. Lab Animals, 18: 351-358.

25. Valle CMR (2008) Estudo morfofuncional de rins de primatas Callithrix jacchus em cativeiro. Thesis (Doctorate in Anatomia dos Animais Domésticos e Silvestres) - Faculdade de Medicina Veterinária e Zootecnia, Universidade de São Paulo, São Paulo.

26. Wadsworth PF, Budget DA, Forster ML (1981) Organ weight data in juvenile and adult marmosets (Callithrix jacchus). Lab Animals, 15: 385-388. 